\title{
"SAIO DA VIDA PARA ENTRAR NA HISTÓRIA" - pontos de vista, responsabilidade enunciativa coletiva e polêmica pública na Carta-Testamento de Getúlio Vargas
}

\author{
Maria das Graças Soares Rodrigues ${ }^{1}$ \\ Luis Passeggi ${ }^{2}$ \\ João Gomes da Silva Neto ${ }^{3}$
}

\begin{abstract}
The testament letter reflects the national dissension that prevailed in Brazil, under President Getúlio Vargas government (1951-1954). It is structured based on the actions taken by him, being the maximum representative of Brazil, and on the guidelines, recommendations and advice about the ideological legacy he left for the common people, the proletariat. Getulio Vargas' statement, as the first person speaker and enunciator (L1 / E1), translates the political polarization that dominated Brazil, whose democracy was threatened. When Vargas recounts his actions, taking enunciative responsibility, he reveals the ethos of one who ruled for the people, who is therefore deserving of recognition. We aim at addressing the relationship between collective enunciative responsibility (RABATEL, 2008) and public controversy (AMOSSY, 2014) in the testament letter of Getulio Vargas. Therefore, we focus on the notion of point of view (POV). In this direction, we show the POV of L1 / E1 about himself, the POV that L1 / E1 built about his opponents, and the POV he had on the people. The antagonistic relationship arising from the POV of L1 / E1 about himself and the POV that he builds about the opponents is the target argument which allowed us to observe the intersection of collective enunciative responsibility and public controversy.
\end{abstract}

Keywords: Collective enunciative responsibility; public controversy; point of view.

Resumo: A carta-testamento reflete o dissenso nacional que predominava no Brasil, no governo do Presidente Getúlio Vargas (1951-1954). Está estruturada a partir do relato das ações realizadas por ele, na condição do mandatário máximo do Brasil, e das orientações, recomendações e aconselhamentos acerca do legado ideológico que ele deixou para os humildes, para o povo, o proletariado. O relato de Getúlio Vargas, o locutor enunciador primeiro (L1/E1), traduz a polarização política que dominava o Brasil, cujo regime democrático estava ameaçado. Quando Getúlio Vargas relata suas ações, assumindo a responsabilidade enunciativa, mostra o ethos daquele que fez pelo povo, que é, portanto, merecedor do reconhecimento. Propomo-nos, pois, a tratar a relação existente entre responsabilidade enunciativa coletiva (RABATEL, 2008) e polêmica pública (AMOSSY,

1 (UFRN) gracasrodrigues@gmail.com

2 (UFRN) luispasseggi.ufrn@gmail.com

3 (UFRN) joao.gsnt@gmail.com 
2014), nessa carta-testamento. Para tanto, também focalizamos a noção de ponto de vista (PDV). Nessa direção, mostramos o PDV do L1/E1 acerca de si próprio, o PDV que L1/E1 construiu dos adversários e o PDV que ele tinha sobre o povo. A relação antagônica decorrente do PDV de L1/E1, acerca de si próprio, e do PDV, que ele constrói dos adversários, constitui a visada argumentativa que nos permitiu observar a interseção entre responsabilidade enunciativa coletiva e polêmica pública.

Palavras-chave: Responsabilidade enunciativa coletiva; polêmica pública; ponto de vista.

\section{Introdução}

Neste artigo, discutiremos possíveis efeitos de sentido decorrentes da "textura enunciativa" (MOIRAND, 2000), tendo por objeto a carta-testamento do então presidente Getúlio Vargas, a qual foi considerada pelo jornalista Nery $(2014$, p. 72), como "um documento revolucionário, manifesto aos trabalhadores denunciando o imperialismo americano". Getúlio Vargas, em seu mandato de 1951-1954, viveu um período muito conflituoso, cuja tensão acirrou-se, em consequência a vários atos que beneficiavam a classe trabalhadora, como, por exemplo, por ter reajustado em 100\% o salário mínimo, que estava congelado, há dez anos.

O país estava dividido, de um lado, o poder instituído, do outro lado, a oposição ferrenha. Evocamos Lira Neto (2014, p. 350-1), quando relata que:

para muitos, ele foi o grande responsável pela modernização do Brasil, ao pôr em prática um modelo nacional-desenvolvimentista capaz de direcionar, em pouco mais de duas décadas, um país agrário para o rumo efetivo da industrialização. Sob essa mesma perspectiva, a vasta legislação trabalhista, ao reconhecer como legítimas as reivindicações dos operários e demais trabalhadores urbanos, instituiu o necessário equilíbrio na relação entre patrões e empregados, superando os resquícios da escravatura mais arcaica. A Petrobrás, a Companhia Siderúrgica Nacional, a Eletrobrás e a CLT seriam as heranças mais eloquentes do getulismo, fenômeno que teria conseguido estabelecer as bases de uma aliança singular entre capital e trabalho, possibilitando a própria gênese do capitalismo no Brasil. Para outros, contudo, o chamado populismo varguista seria a expressão mais pronta e acabada do uso das massas como instrumento de dominação política. A incorporação dos trabalhadores e das classes médias no cenário nacional teria sido apenas uma forma de legitimar o líder autoritário e personalista, dando sustentação a um projeto de poder autocrático e incompatível com a verdadeira democracia. Daí o desdém atávico de Getúlio pelo sistema representativo pelo parlamento e - após rasgar duas Constituições e evitar assinar uma terceira - pelo ordenamento constitucional. Amado e odiado com simultânea veemência, venerado e satanizado com idêntico ardor, Getúlio segue a dividir, provocar contendas, gerar reações passionais. Por certo, o melhor caminho para compreendê-lo, em perspectiva histórica, não é o da devoção sincera ou da negação irrestrita.

(Grifos nossos)

Essa transcrição da contextualização que Lira Neto (2014) faz do cenário político do Brasil, em 1954, mostra o antagonismo nacional, em relação a Vargas, o presidente populista. Nas palavras de Charaudeau (2011, p. 101), "quando os sujeitos falantes são atores políticos, observa-se que 'populista' é empregado tanto pela direita como pela esquerda para estigmatizar o partido adverso ou para se defender contra o estigma". O uso desse termo, ainda que por atores oponentes, tanto pela direita, como pela esquerda, veicula um 
valor semântico, que qualifica o dirigente público como aquele que não honra as relações institucionais de caráter público, mas que faz uso delas para projetar um ethos do perfeito, daquele que defende o povo, até mesmo com atitudes paternalistas, perante os adversários, e, paradoxalmente, também projeta uma imagem de vítima, como foi o caso de Getúlio Vargas, cuja carta-testamento mostra o gesto extremo dele: oferecer a vida em holocausto.

Foi, pois, em meio ao dissenso político, que dominava o Brasil, que a carta-testamento, objeto de nossa análise, foi induzida. Nas palavras de Nery (2014 p. 73), "o velho era um gênio. Tinha mandado seu amigo Maciel Filho preparar uma Carta-testamento para qualquer necessidade. Com duas laudas de papel matou os adversários todos juntos. Deixou algumas frases arrasadoras para ficarem na História”.

Era, pois, 24 de agosto de 1954, quando a crise política nacional teve seu desenlace com o suicídio do então Presidente Getúlio Vargas, o qual deixou uma carta que foi nomeada pela imprensa de "carta-testamento". Essa carta reflete a polêmica pública que levou seu autor ao extremo. A propósito da polêmica pública, evocamos Amossy (2014, p. 17), quando explica: "a polêmica pública está indissoluvelmente ligada ao desacordo. É por isso que ela pesa nas sociedades nas múltiplas formas do dissenso". De fato, o desacordo reinava de Norte a Sul no país, o segundo mandato do Presidente Getúlio Vargas foi marcado por insatisfação política e econômica. Militares, grupos empresariais e partidos de oposição pressionavam o presidente para que ele renunciasse, por seu turno, ele não concordava. O dissenso estava posto. De acordo com D’Araujo (2011, p. 42), o presidente "concordou em tirar uma licença de 90 dias, caso as forças armadas mantivessem a ordem, mas negou-se a uma renúncia definitiva, recebendo solidariedade do ministério". Apesar de ser um político que, por um lado, contava com o apoio das massas, por outro lado, "militares da terra, mar e ar [...] exigiam a severa punição de todos os crimes de responsabilidade, de corrupção, de acobertamento e proteção de suspeitos e culpados, que já tenham sido ou venham ainda a ser postos em evidência no decurso das averiguações." (LIRA NETO, 2014, p. 320). Enfim, nesse contexto, a articulação dos apoios, contando com os trabalhadores, não prosperou porque os militares estavam implacáveis.

Essa carta-testamento, nosso objeto de análise, é o registro do enceramento da crise pública, política, econômica, além das denúncias de corrupção por membros do governo, nos anos de 1951 a 1954. Para melhor compreendê-la, a partir de uma perspectiva, focalizaremos os seguintes dispositivos enunciativos: responsabilidade enunciativa coletiva, pontos de vista e polêmica pública.

\section{Responsabilidade enunciativa coletiva, pontos de vista e polêmica pública}

Discutiremos essas noções anunciadas no título da seção, a partir de alguns autores, entre eles, Adam (2011[2008]); Adam e Lugrin (2006); Rabatel (2008, 2008a, 2008b, 2015, 2015a); Amossy (2008, 2014); Charaudeau (2011); Peñafiel (2011); Oger e Ollivier -Yaniv (2006); Grangé (2003); Rodrigues, Passeggi e Silva Neto (2010); Rodrigues, Silva Neto, Passeggi e Marquesi (2012); Lourenço e Rodrigues (2013); Rodrigues, Silva Neto e Passeggi (2014); Rodrigues e Passeggi (2015); Lourenço (2015).

A responsabilidade enunciativa, de acordo com Adam e Lugrin (2006, p. 1),

é uma noção ética e jurídica que, se redefinida enunciativamente, pode ser linguisticamente abordada a partir de seu núcleo constitutivo: (a) a construção de uma representação discursiva (doravante $\mathrm{Rd}$ ), (b) a assunção da responsabilidade enunciativa dessa $\mathrm{Rd}$ ou ponto de vista (doravante PdV) e (c) o valor ilocutório dos atos de discurso, inseparáevl da orientação argumentativa dos enunciados. 
Esses núcleos constitutivos subsidiarão nossa abordagem linguística da responsabilidade enunciativa, nesta seção. Além disso, ampliaremos a discussão sobre a responsabilidade enunciativa propondo uma articulação entre responsabilidade enunciativa coletiva e polêmica pública.

Faz-se mister ressaltar que o plano de texto da carta se constitui de seis parágrafos. Essa unidade usada para segmentar as zonas textuais será considerada para ilustrar a análise. A respeito do corpus, acrescentamos que Lira Neto (2014, p.346) relata que "o presidente não sabia escrever à máquina. $\mathrm{O}$ esboço escrito por ele à mão fora passado a limpo - e, talvez, reescrito - pelo amigo José Soares Maciel Filho, que lhe deu a redação final.”

Identificamos na carta-testamento, objeto de nossa reflexão, zonas textuais que mostram a ocorrência da responsabildiade enunciativa coletiva. Rabatel (2008, p. 47) explica essa noção, dizendo que

se apoia nas representações e nas práticas a partir das quais um indivíduo ou um grupo levam em consideração os problemas de uma comunidade [...] implica a necessidade de colocar em diálogo pontos de vista diferentes, até mesmo conflituosos, a fim de ajudar na solução de problemas em um sentido útil à sociedade. Em outras palavras, o sentimento da responsabilidade carrega em si, certamente, a preocupação com seus interesses (pessoais, categoriais, de classe, etc.), mas também leva em consideração os interesses de outrem, a fim de fazer emergir compromissos meritórios e aceitáveis para o conjunto do corpo social. [...] a busca por um ponto de acordo passa por um debate argumentado [...] não se limita, portanto, ao afrontamento polêmico das partes e favorece a entrada em cena de mediadores que defendem compromissos positivos. Tal concepção da responsabilidade coletiva questiona a função dos mediadores eminentes nas sociedades modernas, que são os responsáveis políticos e os jornalistas.

(Grifos nossos)

A incorporação dos interesses de classes, grupos, sindicatos, partidos políticos, instituições militares, empresas de economia mista, empresas públicas, empresas privadas, entre outros, à plataforma de um governante é, por exemplo, uma forma de configurar a responsabilidade enunciativa coletiva. Assim, para desenvolver nosso propósito, passaremos a cotejar a caracterização da responsabilidade enunciativa coletiva e de polêmica pública com os atos enunciativos de Getúlio Vargas, o L1/E1 da carta-testamento, aos quais subjazia o confronto do legado ideológico dele, constantemente contestado pelos grupos que queriam destituí-lo do poder máximo do país. O cenário nacional era de uma profunda crise pública, em todas as dimensões, conforme transcrição ipsis litteris de Silva (2014, p. 268), mostrando que um dos principais jornais cariocas de oposição a Getúlio Vargas expressava o desejo dos adversários (políticos, militares do alto escalão e grandes empresários): a renúncia do Presidente Getúlio Vargas.

[...] o estardalhaço da Tribuna atinge proporções inimagináveis: 'Presidente da República: renuncia à presidência para salvar a República - Getúlio Vargas: deixa o poder para que o teu país, que é o nosso país, possa respirar nos dias de paz que os teus lhe roubaram - Sai do poder, Getúlio Vargas, se queres merecer algum respeito como criatura humana, já que perdeste o direito de ser acatado como figura humana'.

Nesse contexto, o então presidente Getúlio Vargas era rotulado de populista. Nessa direção, evocamos Charaudeau (2011, p. 101), quando diz: "para a direita, a esquerda 
é populista por manipular as classes operárias e populares; para a esquerda, a direita é populista porque manipula as classes médias e populares (pouco politizadas)[...] nos dois casos populista é o outro"[...]. Rotular alguém de populista constitui, assim, uma relação paradoxal de pontos de vista, tendo em vista o alinhamento ideológico divergente do posicionamento político, de tal forma que a direita usa um critério ("a esquerda é populista por manipular as classes operárias e populares"), enquanto a esquerda usa outro ("a direita é populista porque manipula as classes médias e populares (pouco politizadas)"). Apesar de posições ideológicas diferentes, há uma interseção entre esses pontos de vista que constitui o cerne da argumentação para taxar outrem de populista: manipulação de determinadas classes sociais.

Situada essa contextualização, passaremos a refletir acerca da relação entre os enunciados de Getúlio Vargas e as noções de a responsabilidade enunciativa coletiva e a polêmica pública, a partir da carta-testamento transcrita a seguir:

$\S 1$ "Mais uma vez, as forças que os interesses contra o povo coordenaram novamente, se desencadearam contra mim.

§2 Não me acusam, me insultam: não me combatem, caluniam e não me dão o direito de defesa. Precisam sufocar a minha voz e empedir a minha ação, para que eu não continue a defender, como sempre defendi, o povo e principalmente os humildes. Sigo o destino que me é imposto. Depois de decênios de domínio e espoliação dos grupos econômicos e financeiros internacionais, fiz-me chefe de uma revolução e venci. Iniciei o trabalho de libertação e instaurei um regime de liberdade social. Tive que renunciar. Voltei ao governo nos braços do povo. A campanha subterrânea dos grupos internacionais aliou-se a dos grupos nacionais revoltados contra o regimem de garantia do trabalho. A lei de lucros extraordinários foi detida no congresso. Contra a justiça da revisão do salário mínimo se desencadearam os ódios. Quis creara liberdade nacional na potencialização das nossas riquezas através da Petrobras, e mal começa esta a funcionar a onda de agitação se avoluma. A Eletrobras foi obstaculada até o desespero. Não querem que o trabalhador seja livre. Não querem que o povo seja independente. $\S 3$ Assumi o governo dentro da espiral inflacionária, que destruia os valores de trabalho. Os lucros das emprêsas estrangeiras alcançavam até $500 \%$ ao ano. Nas declarações de valores do que importavamos existiam fraudes constatadas de mais de cem milhões de dólares por ano. Veio a crise do café, valorizou-se o nosso principal produto. Tentamos defender seu preço e a resposta foi uma violenta pressão sobre a nossa economia a ponto de sermos obrigados a ceder.

$\S 4$ Tenho lutado mes a mes, dia a dia, hora a hora, resistindo a uma agressão constante, incessante, tudo suportando em silencio, tudo esquecendo, renunciando a mim mesmo, para defender o povo que agora se queda desamparado. Nada mais vos posso dar a não ser meu sangue. Se as aves de rapina querem o sangue de alguem, querem continuar sugando o povo brasileiro, eu ofereço em holocausto a minha vida. Escolho este meio de estar sempre convosco. Quando vos humilharem sentireis minha alma sofrendo a vosso lado. Quando a fome bater a vossa porta, sentireis em vosso peito a energia para a luta por vos e vossos filhos. Quando vos vilipendiarem, sentireis no meu pensamento a força para a reacão. Meu sacrifício nos manterá unidos e meu nome será a vossa bandeira de luta.

§5 Cada gota de meu sangue será uma chama imortal na vossa consciência e manterá a vibração sagrada para a resistência. Ao ódio respondo com o perdão. E aos que 


\section{Conexão Letras}

pensam que me derrotaram respondo com a minha vitória. Era escravo do povo e hoje me liberto para a vida eterna. Mas esse povo de quem fui escravo, não mais será escravo de ninguem. Meu sacrifício ficará para sempre em sua alma e meu sangue será o preço do seu resgate.

§6 Lutei contra a espoliação do Brasil. Lutei contra a espoliação do povo. Tenho lutado de peito aberto. O ódio as infamias, a calunia, não abateram meu ânimo. Vos dei a minha vida. Agora ofereço a minha morte. Nada receio. Serenamente dou o primeiro passo no caminho da eternidade e saio da vida para entrar na Historia."

Para tratar da responsabilidade enunciativa coletiva, focalizaremos a noção de ponto de vista $(\mathrm{PDV})^{4}$, como a posição que o L1/E1 (locutor enunciador primeiro) assume em relação a um(a) determinado(a) tema, situação, pessoa, etc., ou seja, trata-se de uma avaliação de L1/E1 acerca de um objeto alvo da apreciação. Essa forma simples de explicar o PDV ancora-se em explicações de Rabatel (2008, p.11), a saber:

O PDV, antes de ser um conceito linguístico, é inicialmente uma postura cognitiva e psicossocial, que tem o indivíduo ao se colocar no lugar do outro, até mesmo de todos os outros, para melhor poder refletir sobre a própria postura, certamente para poder emitir um ponto de vista comum que nem estava escrito no início, nem na soma dos PDV particulares.

Por seu turno, François (2015, p. 21) explica que o "termo ponto de vista se desloca sem dificuldade do domínio do visual ao do discurso. Mas nada impede de considerar que nossas formas silenciosas de sentir constituem pontos de vista sobre um mesmo objeto".

Temos uma interseção entre a explicação de Rabatel (2008), reflexão sobre outrem, assim como, acerca de si próprio e a de François (2015), as "formas silenciosas de sentir". Isso mostra que o PDV é um dispositivo enunciativo carregado de subjetividade do(s) enunciador(es). Na carta-testamento, o L1/E1 emite enunciados com sintagmas nominais marcados pela subjetividade, conforme destacamos: "lucros extraordinários", "uma agressão constante", "os ódios", "uma violenta pressão", entre outros que poderíamos ressaltar. Esses sintagmas nominais constituem o PDV do L1/E1 acerca das forças contrárias a ele, que exercia a função de presidente do Brasil. Isso fica bem evidente, quando ele diz: "Contra a justiça da revisão do salário mínimo se desencadearam os ódios". O que para o L1/E1 era justo será que se ajustava às condições sócio-econômicas do país? As empresas podiam cumprir com as despesas patronais?

Evocamos mais uma vez as palavras de Rabatel (2008, p.12) acerca do PDV, quando esclarece:

a noção de ponto de vista é complexa, não se pode ter mais complexa, tanto ela se constitui de domínios variados, indo da vista ("ter um belo ponto de vista") à expressão de uma opinião mais ou menos defendida, mas distinta das verdades científicas ("não partilho desse ponto de vista") passando pela adoção de um centro de perspectiva narrativo [...] a uma informação importante [...]

4 O ponto de vista (PdV) é considerado por Adam e Lugrin (2006, p. 1) como a representação discursiva. Optamos por usar a expressão ponto de vista e grafá-la como o faz Rabatel (2008), em seus trabalhos, a saber: PDV. 
A carta-testamento é um dado complexo, sua compreensão passa pela revisitação ao momento histórico, político, econômico e social que vivia o Brasil, em 1954. Essa postura, certamente, viabilizará a compreensão dos PDV do L1/E1, assim como dos enunciados que ele emite, assumindo a responsabilidade enunciativa pelo conteúdo proposicional.

Convém esclarecer que a carta-testamento está estruturada a partir do relato das ações realizadas por L1/E1, na condição do mandatário máximo do Brasil, e das orientações, recomendações e aconselhamentos acerca do legado ideológico que ele deixa para os humildes, para o povo, o proletariado. Há, assim, atos de discurso que veiculam efeitos de sentido do que foi realizado e aqueles que são diretivos, ou seja, aqueles que predizem, recomendam, orientam, determinam, ordenam. No dizer de Vanderveken (1997, p. 15), são "atos ilocutórios como pedidos, perguntas, preces, convites, ordens, conselhos, recomendações que têm um objetivo diretivo. Quando realizados, os locutores exprimem uma proposição, a fim de tentar fazer com que o interlocutor realize, mais tarde, a ação que eles representam". No caso da carta, trata-se de atos de discurso ilocutórios diretivos que se alinham à noção semântica de predição, orientação e recomendação. A seguir, analisaremos excertos da carta, visando a mostrar como isso se manifesta discursivamente.

\section{Exemplo 01}

Quando vos humilharem sentireis minha alma sofrendo a vosso lado.

\section{Exemplo 02}

Quando a fome bater a vossa porta, sentireis em vosso peito a energia para a luta por vos e vossos filhos.

\section{Exemplo 03}

Quando vos vilipendiarem, sentireis no meu pensamento a força para a reação.

\section{Exemplo 04}

Meu sacrifício nos manterá unidos e meu nome será a vossa bandeira de luta.

Nos três primeiros exemplos, observamos a recorrência da forma verbal "sentireis", ou seja, L1/E1 prediz o que acontecerá, que sentimento o povo vivenciará. No exemplo 01, "sentireis" se atualiza com o sentido de "reconhecereis". No exemplo 02, a representação discursiva que podemos fazer de "sentireis" corresponde a um ter, a algo que estará disponível dentro de cada um, pulsando, estimulando, instigando à ação. No exemplo 03, temos uma visada argumentativa, reiterando o legado ideológico deixado por L1/E1, quando diz: "sentireis no meu pensamento a força para a reação". Há uma orientação que aponta a fonte da solução: o pensamento de L1/E1, ou seja, o plano das ideias. Por fim, no exemplo 04, L1/E1 ressalta a aliança selada para eternidade entre ele e o povo.

Ilustraremos, a seguir, o ponto de vista (PDV) que Getúlio Vargas, o L1/E1, tem de si próprio, a respeito do povo e também acerca dos opositores dele. Há um movimento dialógico de remissão a uma anterioridade, quando L1/E1 começa a carta, asseverando: "Mais uma vez, as forças que os interesses contra o povo coordenaram novamente, se desencadearam contra mim". Temos "mais uma vez" e "novamente" que apontam recorrência de ações desencadeadas pelas "forças" contrárias a L1/E1 e aos "interesses contra o povo". A seguir, sintetizaremos no quadro 01 alguns dos PDV subjacentes aos atos de discurso que promovem a semiotização do dizer de L1/E1. 
Quadro 01 - PDV de L1/E1 acerca de si, do povo e da oposição

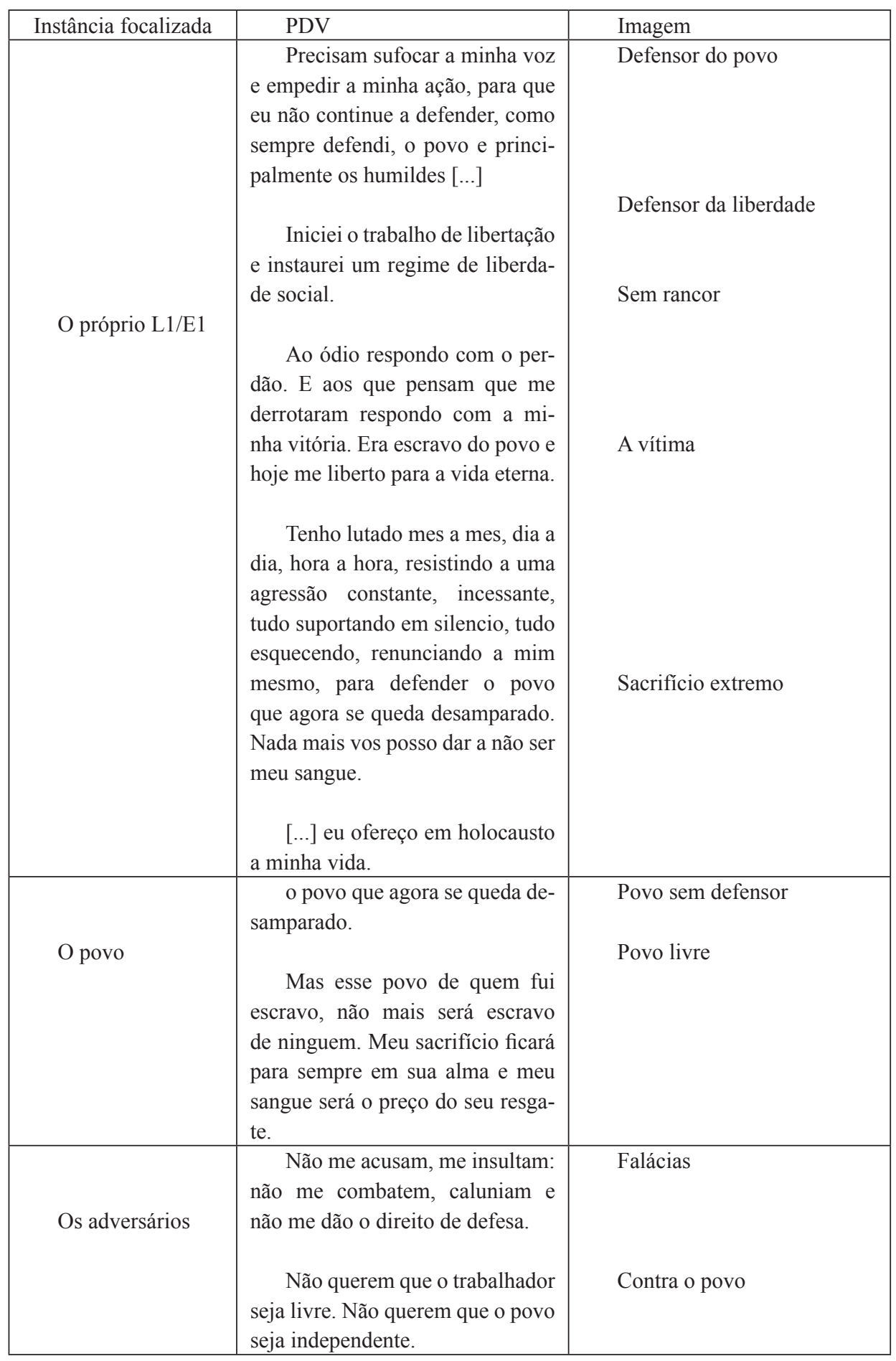


Os PDV destacados no quadro 01 evidenciam que L1/E1 constrói um ethos de salvador do povo, da classe operária, porém os adversários de L1/E1 (as forças contra o povo) o "insultam", o "caluniam". O conjunto dos pontos de vista dessas instâncias enunciativas: (1) L1/E1; (2) os adversários de L1/E1 e do povo e (3) o povo, no plano da superfície textual e discursiva, no nível pragmático e enunciativo, configura a responsabilidade enunciativa coletiva, tendo em vista L1/E1 defender os interesses do corpo social proletariado e mais humilde, em outras palavras, os interesses de outrem integravam a plataforma de Getúlio Vargas. Há, pois, um jogo enunciativo em que interesses estão polarizados, de um lado, o presidente, que era o mediador dos interesses do povo, do proletariado e dos mais humildes, do outro lado, os adversários, inclusive, a grande imprensa, tendo entre outros grandes jornalistas, Carlos Lacerda, ferrenho inimigo do presidente. Pontos de vista conflituosos (RABATEL, 2008) constituem a cena discursiva da carta-testamento de Getúlio Vargas. A seguir, representamos com a figura 01 as instâncias que singularizam a responsabilidade enunciativa coletiva na carta-testamento.

\section{Figura 01 - L1/E1 e instâncias enunciativas centrais evocadas}

\section{$\mathrm{L} 1 / \mathrm{E} 1$}

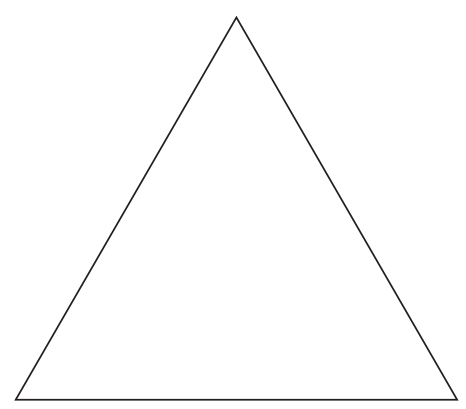
As forças (e2)
O povo (e3)

O L1/E1 mobiliza formas verbais na 3a . pessoa do plural "acusam”, "insultam", "combatem" e "caluniam" que seguem uma gradação que vai do ato enunciativo de "acusar" a "caluniar", uma vez que a acusação não se sustenta, veiculando, assim, o valor semântico de calúnia. Segundo o PDV de L1/E1, tudo não passa de calúnia. Essa escolha lexical de L1/E1 dá pistas ao interlocutor para compreender a responsabilidade enunciativa coletiva das duas instâncias inimigas: (1) L1/E1, que se constitui de si próprio e dos interesses do povo, dos humildes, dos quais defende a liberdade social e (2) e $2^{5}$, que se constitui das forças contrárias (políticos, militares, imprensa, etc.), as quais discordam dos procedimentos institucionais postos em prática por L1/E1. Ancoramo-nos em Raba-

5 D’ARAÚJO, Maria Celina (Org.). Getúlio Vargas. Brasília: Edições Câmara, 2011.

HENRIQUES, Affonso. Ascensão e queda de Getúlio Vargas: o maquiavélico. Rio de Janeiro: Record, 1958. (vol.1)

LIRA NETO. Getúlio: da volta pela consagração popular ao suicídio (1945-1954). 1.ed. São Paulo: Companhia das Letras, 2014. (vol.3) 
tel (2008, p. 47), quando explica a concepção de responsabilidade enunciativa coletiva, como sendo aquela que "questiona a função dos mediadores eminentes nas sociedades modernas, que são os responsáveis políticos e os jornalistas.” Há, por um lado, a indignação de L1/E1 (político, presidente de uma nação) por estar sendo acusado, insultado, combatido e caluniado e, por outro lado, a ação de e2 (políticos, militares, imprensa, etc.) que "acusam", "insultam", "combatem" e "caluniam" L1/E1.

A construção da responsabilidade enunciativa coletiva está estreitamente ligada à polêmica pública, nos termos de Amossy $\left(2014^{6}\right)$, conforme reflete o corpus, em análise: dissenso, desacordo. A carta-testamento evidencia a dicotomia que dominava o Brasil. O excerto, a seguir, remete ao conflito, através do relato que o L1/E1 faz de sua trajetória e ações, no exercício da função de presidente, visando a justificar a decisão de pôr fim à sua vida. Para tanto, L1/E1 assume a responsabilidade enunciativa do conteúdo proposicional dos enunciados:

Sigo o destino que me é imposto. Depois de decênios de domínio e espoliação dos grupos econômicos e financeiros internacionais, fiz-me chefe de uma revolução e venci. Iniciei o trabalho de libertação e instaurei um regime de liberdade social. Tive que renunciar. Voltei ao governo nos braços do povo. A campanha subterrânea dos grupos internacionais aliou-se a dos grupos nacionais revoltados contra o regimem de garantia do trabalho. A lei de lucros extraordinários foi detida no congresso. Contra a justiça da revisão do salário mínimo se desencadearam os ódios. Quis creara liberdade nacional na potencialização das nossas riquezas através da Petrobras, e mal começa esta a funcionar a onda de agitação se avoluma. A Eletrobras foi obstaculada até o desespero. Não querem que o trabalhador seja livre. Não querem que o povo seja independente.

Ressaltamos a polarização projetada pelos atos enunciativos de L1/E1, conforme segue:

\section{Quadro 02 - L1/E1 emite PDV sobre si próprio e sobre as forças contrárias}

\begin{tabular}{|l|l|}
\hline \multicolumn{1}{|c|}{ L1/E1 } & \multicolumn{1}{c|}{ Forças contrárias } \\
\hline $\begin{array}{l}\text { Sigo o destino que me é imposto } \\
\text { fiz-me chefe de uma revolução e }\end{array}$ & {$[\ldots]$ e espoliação dos grupos econômicos e } \\
venci. & financeiros internacionais $[\ldots]$ \\
Iniciei o trabalho de libertação e instau- & A campanha subterrânea dos grupos inter- \\
nacionais aliou-se a dos grupos nacionais \\
rei um regime de liberdade social. Tive & revoltados contra o regimem de garantia \\
que renunciar. & do trabalho. \\
Voltei ao governo nos braços do povo. & A lei de lucros extraordinários foi detida \\
{$[\ldots]$} & no congresso. \\
Quis crear a liberdade nacional na poten- & Contra a justiça da revisão do salário míni- \\
cialização das nossas riquezas através da & mo se desencadearam os ódios. \\
Petrobras & {$[\ldots]$ e mal começa esta a funcionar a onda } \\
& de agitação se avoluma. \\
& A Eletrobras foi obstaculada até o deses- \\
& pero. Não querem que o trabalhador seja \\
& livre. \\
& Não querem que o povo seja independente \\
\hline
\end{tabular}

6 Vide introdução. 
O relato de L1/E1 traduz a polarização política que dominava o Brasil, cujo regime democrático estava ameaçado. Quando ele relata suas ações, assumindo a responsabilidade enunciativa, mostra o ethos daquele que fez pelo povo, que é, portanto, merecedor do reconhecimento, ao enunciar:"voltei nos braços do povo", ou seja, teve o reconhecimento do povo, dos humildes, teve uma verdadeira consagração, porém, a respeito das "forças contrárias", relata as consequências da aliança entre os grupos internacionais com os grupos nacionais: "revolta" por conta do regime de garantia do trabalho e "ódio" pela atualização monetária do salário mínimo. L1/E1 infere que essas forças contrárias "Não querem que o trabalhador seja livre. Não querem que o povo seja independente". Esse jogo enunciativo de L1/E1 através dos PDV de si próprio e acerca das forças contrárias conduz o interlocutor para um viés da disputa: L1/E1 e o povo são vítimas.

Acompanhamos Amossy (2014, p.175), quando postula que "a polêmica [...] é uma modalidade argumentativa e não um simples discurso agressivo. É confronto, forte oposição de discurso acerca de uma questão controversa". A carta-testamento revela exatamente o conflito, o confronto, a discordância, constituindo, assim, ainda que antagonicamente, uma dinâmica de pontos de vista convergentes e divergentes, na busca por melhorias para o corpo social. Nessa direção, ressaltamos o jogo enunciativo de antagônico que estrutura a visada argumentativa, ao longo da carta-testamento, com o último parágrafo, a fim de que possamos observar que L1/E1 mantém, até o final da carta, esse movimento dos PDV de si próprio, do povo e das forças contrárias.

Lutei contra a espoliação do Brasil. Lutei contra a espoliação do povo. Tenho lutado de peito aberto. O ódio as infamias, a calunia, não abateram meu ânimo. Vos dei a minha vida. Agora ofereço a minha morte. Nada receio. Serenamente dou o primeiro passo no caminho da eternidade e saio da vida para entrar na Historia.

L1/E1 encerra a carta enaltecendo seu ethos positivo, assumindo a responsabilidade enunciativa pelo conteúdo proposicional dos atos enunciativos que expressam seu PDV acerca de si e das forças oponentes. L1/E1 usa o verbo "lutar", que evoca a existência de adversário(s), mais especificamente, daquele(s) que praticava(m) a espoliação do Brasil e do povo. Ademais, o conjunto das formas verbais na $1^{\mathrm{a}}$. pessoa do singular caracteriza mais que a assunção da responsabilidade enunciativa, que esses enunciados são atos de discurso ilocutórios performativos, realizados por enunciados declaratórios, de acordo com a classificação tipológica proposta e revisitada pelo próprio Vanderveken (1997, 2001, 2013). Por meio desses atos ilocutórios performativos, L1/E1cria no mundo fatos tanto linguísticos, como extra-linguísticos, como é o caso do suicídio do presidente Getúlio Vargas, anunciado na carta-testamento "agora ofereço a minha morte. Nada receio. Serenamente dou o primeiro passo no caminho da eternidade e saio da vida para entrar na Historia."

Para encerrarmos essa seção, mostraremos, com a figura 02, a interseção entre responsabilidade enunciativa coletiva, nos termos de Rabatel (2008, p. 47), “os problemas de uma comunidade [...] implica a necessidade de colocar em diálogo pontos de vista diferentes, até mesmo conflituosos", e a polêmica pública, a perspectiva de Amossy (2014, p.17), “está indissoluvelmente ligada ao desacordo. É por isso que ela pesa nas sociedades nas múltiplas formas do dissenso". 
Figura 02 - Interseção entre responsabilidade enunciativa coletiva e polêmica pública

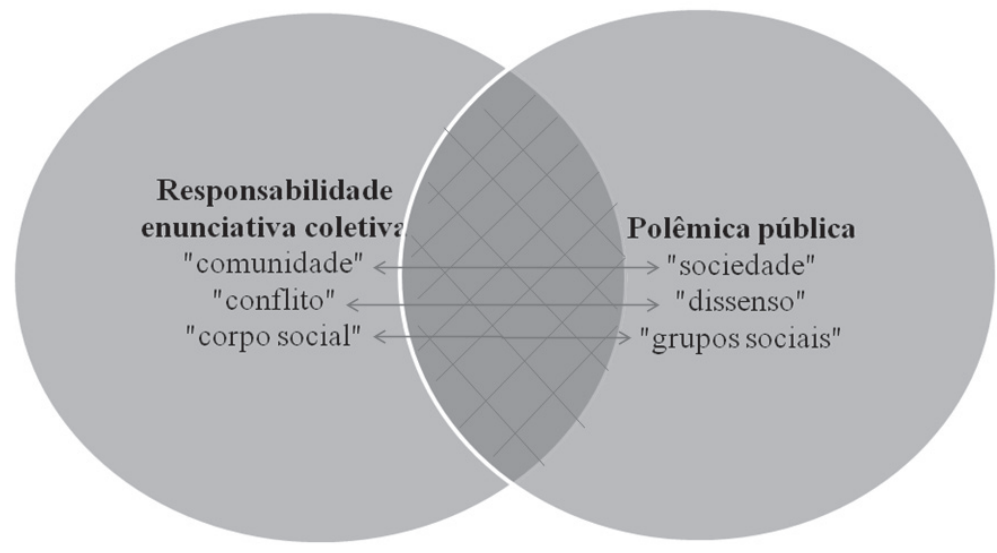

\section{Considerações finais}

A análise da carta-testamento evidencia uma estreita relação entre a responsabilidade enunciativa coletiva (RABATEL, 2008) e a polêmica pública (AMOSSY, 2014). Nessa direção, aludimos à interseção entre esses dois dispositivos enunciativos, isto é, a recorrência da tensão discursiva ao longo do texto, cuja estrutura revela, pois, conflito público no âmbito do conjunto do corpo social. Getúlio Vargas, o L1/E1, sustentou a argumentação para justificar o suicídio, remetendo a duas instâncias enunciativas: (1) e/2, "as forças contrárias", e (2) e/3, "o povo", exatamente os dois grandes adversários, porém L1/E1 era aliado do povo, logo de e/3 (vide figura 1, deste artigo). Assim, na arena discursiva, temos de um lado: L1/E1 + e/3 e do outro lado: e/2.

O dissenso está posto, desde o primeiro parágrafo da carta, quando o L1/E1 a inicia declarando: "Mais uma vez, as forças que os interesses contra o povo coordenaram novamente, se desencadearam contra mim." Assim, os elementos textuais e discursivos (verbais), como, por exemplo, "as forças", "contra o povo" e "contra mim", no primeiro parágrafo, subsidiaram a análise que nos permite postular que a responsabilidade enunciativa coletiva e a polêmica pública podem orientar a identificação, descrição, análise e interpretação de gêneros discursivos / textuais que tenham por propósito comunicativo temas públicos que mobilizam vozes em discordância.

\section{Referências}

ADAM, Jean-Michel. Introduction. In: ADAM, Jean-Michel (Dir.). Faire texte:

frontières textuelles et opérations de textualisation. Besançon: Presses Universitaires de Franche-Comté, 2015, p.11-33.

ADAM, Jean-Michel. A linguística textual: introdução à análise textual dos discursos. São Paulo: Cortez, 2011[2008].

ADAM, Jean-Michel; LUGRIN, Gilles. Effacement énonciatif et diffraction co-textuelle de la prise en charge des énoncés dans les hyperstructures journalistiques. In: Semen, n. 22, 2006, p. 1-20. Disponível em:< http://semen.revues.org/4381>. Acesso em: 30 de dezembro de 2015. 
AMOSSY, Ruth. Responsabilité journalistique et responsabilité politique - Le journal Ha-aretz face à la Commission Winograd sur la deuxième guerre du Liban. In:

Questions de communication, 2008, p. 109-127.

AMOSSY, Ruth. Apologie de la polémique. Paris: PUF, 2014.

CHARAUDEAU, Patrick. Réflexions pour l'analyse du discours populiste. In: Mots Les langages du politique, n.97, 2011, p. 101-116. Disponível em:

$<$ http://mots.revues.org/20534>. Acesso em: 23 de dezembro de 2015.

FERNÁNDEZ LAGUNILLA, Marina; OTAOLA OLANO, Concepción. Aproximación al discurso de la derecha en España, in. Revista de estudios políticos, n. 40, 1984, p.

123-138. Disponível em: $<$ http://dialnet.unirioja.es/descarga/articulo/26792.pdf $>$. Acesso em: 04 de janeiro de 2016.

FERNÁNDEZ LAGUNILLA, Marina. La lengua en la comunicación política: El discurso del poder, vol. 1, Madrid: Arco Libros, 1999.

FERNÁNDEZ LAGUNILLA, Marina. La lengua en la comunicación política: El La palabra del poder, vol. 2, Madrid: Arco Libros, 1999.

FRANÇOIS, Frédéric. Quelques points de vuesurles points de vue. In:

CARCASSONNE, Marie; CUNHA, Dóris; DONAHUE, Christiane; FRANÇOIS, Frédéric; RABATEL, Alain. Points de vuesurle point de vue. Limoges: Lambert-Lucas, 2015, p.7-76.

GRANGÉ, Ninon. Cicéron contre Antoine: la désignation de l'ennemi dans la guerre civile. In: Mots - Les langages du politique, n. 73, 2003, p. 9- 23. Disponível em: $<$ http://mots.revues.org/15512>. Acesso em:28 de dezembro de 2015. LOURENÇO, Maria das Vitórias Nunes Silva. Análise textual dos discursos: responsabilidade enunciativa no texto jurídico. Curitiba: CRV, 2015.

LOURENÇO, Maria das Vitórias Nunes Silva; RODRIGUES, Maria das Graças Soares. Considerações sobre o quadro mediativo e petições iniciais. In: Linha d'Água, n.26, v.2, 2013a, p. 71-86.

MOIRAND Sophie. Variations discursives dans deux situations contrastées de la presse ordinaire, in. CUSIN-BERCHE, F. (Ed.). Les Carnets du Cediscor: Rencontres discursives entre sciences et politique dans les médias, n.6, 2000, p. 45-62.

MOIRAND Sophie. Du traitement différent de l'intertexte selon les genres convoqués dans les événements scientifiques à caractère politique, in. ADAM, Jean-Michel; HERMAN, Thierry; LUGRIN, Gilles (Dirs.). Semen, n. 13, 2001, p. 97-117. Disponível em: < http://semen.revues.org/2646>. Acesso em: 03 de janeiro de 2016.

NERY, Sebastião. Ninguém me contou eu vi: de Getúlio a Dilma. São Paulo: Geração Editorial, 2014.

NETO, Lira. Getúlio - dos anos de formação à conquista do poder (1882 - 1930). 1.ed.

São Paulo: Companhia das Letras, 2014. (Vol. 1).

NETO, Lira. Getúlio - do governo provisório à ditadura do Estado Novo (1930 - 1945).

1.ed. São Paulo: Companhia das Letras, 2014. (Vol. 2).

NETO, Lira. Getúlio - da volta pela consagração popular ao suicídio (1945 - 1954).

1.ed. São Paulo: Companhia das Letras, 2014. (Vol. 3).

OGER, Claire; OLLIVIER-YANIV, Caroline. Conjurer le désordre discursif. Les procédés de «lissage» dans la fabrication du discours institutionnel. In: Mots - Les langages du politique, n. 81, 2006, p. 63-77. Disponível em: $<$ http://mots.revues. org/675>. Acesso em: 28 de dezembro de 2015. 


\section{Conexão Letras}

PASSEGGI, Luis et al. A análise textual dos discursos: para uma teoria da produção co(n)textual de sentido. In: BENTES, Anna Christina; LEITE, Marli Quadros (Orgs.). Linguística de texto e análise da conversação: panorama das pesquisas no Brasil. São Paulo: Cortez, 2010, p. 262-312.

PEÑAFIEL, Ricardo. L'image du peuple. Construction de l'ethos plébéien de Hugo Chávez dans l'émission Aló Presidente. In: Mots - Les langages du politique, n. 96, 2011, p. 1-19. Disponível em: < http://mots.revues.org/20204>. Acesso em:25 de dezembro de 2015.

RABATEL, Alain. Retour sur un parcours en énonciation. In: CARCASSONNE, Marie; CUNHA, Dóris; DONAHUE, Christiane; FRANÇOIS, Frédéric; RABATEL, Alain. Points de vue sur le point de vue. Limoges: Lambert-Lucas, 2015, p. 327-355. RABATEL, Alain. Postures énonciatives, variable générique et stratégies de positionnement. In: ANGERMULLER, Johannes; PHILIPPE, Gilles. Analyse du discours et dispositifs d'énonciation: autour des travaux de Dominique Maingueneau. Limoges: Lambert-Lucas, 2015a, p. 125-135.

RABATEL, Alain. Pour une conception ethique des débats politiques dans les médias répondre de, devant, pour, ou les défis de la responsabilité collective. In: Questions de communication, 2008, p. 47-69.

RABATEL, Alain. Homo narrans: pour une analyse énonciative et interactionnelle du récit. Le point de vue et la logique de la narration. Limoges: Lambert-Lucas, 2008a. (Tomo 1)

RABATEL, Alain. Homo narrans: pour une analyse énonciative et interactionnelle du récit. Dialogisme e polyphonie dans le récit. Limoges: Lambert-Lucas, 2008b. (Tomo 2) RABATEL, Alain. Une histoire du point de vue. Paris: Klincksieck, 1997. RODRIGUES, Maria das Graças Soares; PASSEGGI, Luis. Émotions, argumentation et points de vue dans l'affaire Nafissatou Diallo contre Dominique Strauss-Kahn. Une analyse textuelle et discursive de chroniques de la Folha de São Paulo. In: RABATEL, Alain; MONTE, Michèle; RODRIGUES, Maria das Graças Soares (Dirs.) Comment les médias parlent des émotions: l'affaire Nafissatou Diallo contre Dominique StraussKahn. Limoges: Lambert-Lucas, 2015, p.291-305.

RODRIGUES, Maria das Graças Soares; PASSEGGI, Luis; SILVA NETO, João Gomes. Planos de texto e representações discursivas: a seção de abertura em processos-crime. In: BASTOS, Neusa Barbosa (Org.). Língua portuguesa e lusofonia. São Paulo: EDUC, 2014, p.241-255.

RODRIGUES, Maria das Graças Soares; SILVA NETO, João Gomes; PASSEGGI, Luis. La lettre-testament du président Getúlio Vargas: généricité, structure compositionnelle et représentations. In: MONTE, Michèle; PHILIPPE, Gilles (Dirs.). Genres \& textes: déterminations, évolutions, confrontations. Lyon: PUL, 2014a, p. 253-267.

RODRIGUES, Maria das Graças Soares; PASSEGGI, Luis; SILVA NETO, João Gomes; MARQUESI, Sueli Cristina. A carta-testamento de GetúlioVargas (1882-1954): genericidade e organização textual no discurso político. In: Filologia e linguística portuguesa, n.14, v. 2, 2012, p. 285-307.

RODRIGUES, Maria das Graças Soares; PASSEGGI, Luis; SILVA NETO, João Gomes. “Voltarei. O povo me absolverá...": a construção de um discurso de renúncia. In: RODRIGUES, Maria das Graças Soares; PASSEGGI, Luis; SILVA NETO, João Gomes (Orgs.) Análises textuais e discursivas - metodologia e aplicações. São Paulo: Cortez, 2010, p.150-195. 
SILVA, Juremir Machado da. Getúlio - romance. 6.ed. Rio de Janeiro: Best Bolso, 2014. VANDERVEKEN, Daniel. Towards a Formal Pragmatics of Discourse. In:

International Review of Pragmatics, n.5, 2013, p. 34-69.

VANDERVEKEN, Daniel. Illocutionary Logic and Discourse Typology. In: Revue Internationale de Philosophie: Searle with his Replies, n. 216, 2001, p. 243-255. VANDERVEKEN, Daniel. La logique illocutoire et l'analyse du discours. In: LUZZATI, Daniel et al. (Dirs.). Le Dialogique. Bern: Peter Lang, 1997, p. 59-94. 